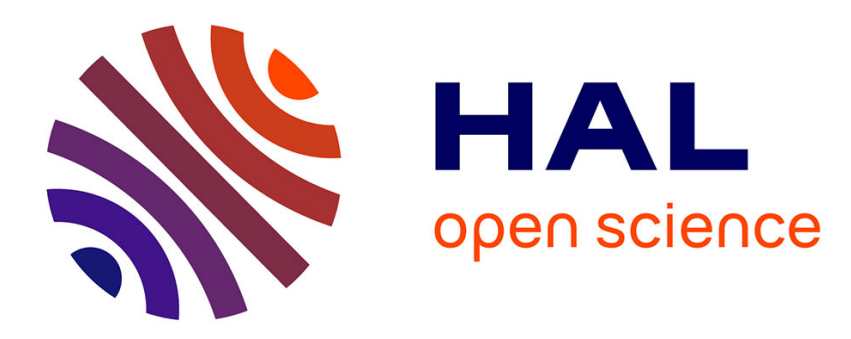

\title{
Incentives for Motivated Agents under an Administrative Constraint
}

\author{
Miltiadis Makris
}

\section{To cite this version:}

Miltiadis Makris. Incentives for Motivated Agents under an Administrative Constraint. Journal of Economic Behavior and Organization, 2009, 71 (2), pp.428. 10.1016/j.jebo.2009.03.013 . hal00683158

\section{HAL Id: hal-00683158 https://hal.science/hal-00683158}

Submitted on 28 Mar 2012

HAL is a multi-disciplinary open access archive for the deposit and dissemination of scientific research documents, whether they are published or not. The documents may come from teaching and research institutions in France or abroad, or from public or private research centers.
L'archive ouverte pluridisciplinaire HAL, est destinée au dépôt et à la diffusion de documents scientifiques de niveau recherche, publiés ou non, émanant des établissements d'enseignement et de recherche français ou étrangers, des laboratoires publics ou privés. 


\section{Accepted Manuscript}

Title: Incentives for Motivated Agents under an Administrative Constraint

Author: Miltiadis Makris

PII: $\quad$ S0167-2681(09)00072-9

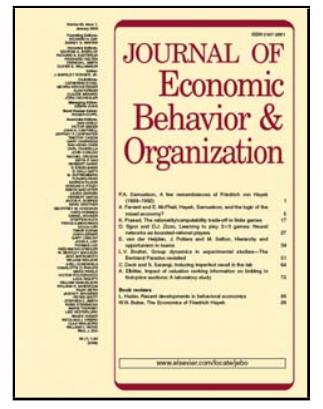

DOI: $\quad$ doi:10.1016/j.jebo.2009.03.013

Reference: $\quad$ JEBO 2344

To appear in: Journal of Economic Behavior \& Organization

Received date: $\quad 3-2-2006$

Revised date: $\quad 3-3-2009$

Accepted date: $\quad 3-3-2009$

Please cite this article as: Makris, M., Incentives for Motivated Agents under an Administrative Constraint, Journal of Economic Behavior and Organization (2008), doi:10.1016/j.jebo.2009.03.013

This is a PDF file of an unedited manuscript that has been accepted for publication. As a service to our customers we are providing this early version of the manuscript. The manuscript will undergo copyediting, typesetting, and review of the resulting proof before it is published in its final form. Please note that during the production process errors may be discovered which could affect the content, and all legal disclaimers that apply to the journal pertain. 
Incentives for Motivated Agents under an Administrative

Constraint

\author{
Miltiadis Makris $\dagger$ \\ Department of Economics, University of Exeter, \\ CMPO, University of Bristol and
}

This version: 2 February 2006

\begin{abstract}
Consider an agent who has an expertise in producing a non-marketable good. This good is valued by a single principal, and there is a verifiable measure of the agent's performance. Crucially, the agent is intrinsically motivated, due to 'warm glow altruism'. In addition, the agent's budget, which is controlled by the principal, must not be less than the monetary performance-cost faced by the agent. This gives rise to a limited-liability constraint. It also restricts the agent's ability to under-report costs. In such environment, we determine the link between the agent's budget and performance. Our results come in contrast to the received solution of the principal-agent problem, and to most in the literature on missionmotivated organisations and public services provision.
\end{abstract}

JEL Classification: D73, D82, H11, H41, L31

Key Words: Mission-orientated Organisations, Asymmetric Information, Administrative Constraint

†I am grateful to Elisabetta Iossa, Clare Leaver and Tim Besley for discussions and suggestions that have improved significantly this work. I would also like to thank Christos Kotsogiannis, Carol Propper and seminar participants at Bristol, Exeter and Crete-2002 for helpful comments prior to this draft. The usual disclaimer applies. Address: Department of Economics, University of Exeter, Streatham Court, Rennes Drive, Exeter EX4 4PU, UK, Tel: ++44 (0)1392 264486, email: M.Makris@exeter.ac.uk. 


\title{
Incentives for Motivated Agents under an Administrative \\ Constraint
}

\author{
Miltiadis Makris* \\ Department of Economics, University of Leicester
}

First Version: 8 May 2005

This version: 3 February 2009

\begin{abstract}
Consider an agent who has an expertise in producing a non-marketable good. This good is valued by a single principal, and there is a verifiable measure of the agent's performance. Crucially, the agent is intrinsically motivated due to 'warm glow altruism'. In addition, the agent's budget, which is controlled by the principal, must not be less than the monetary performance-cost faced by the agent. This gives rise to a limited-liability constraint. It also restricts the agent's ability to under-report costs. In such environment, we determine the link between the agent's budget and performance. Our results come in contrast to the received solution of the principal-agent problem and to most in the literature on missionmotivated organisations and public services provision.
\end{abstract}

JEL Classification: D73, D82, H11, H41, L31

Key Words: Mission-orientated Organisations, Asymmetric Information, Administrative Constraint

*Address: M.Makris, Department of Economics, University of Leicester, University Road, Leicester LE17RH, UK, Tel: ++44 (0)116 2525645, Fax: +44 (0)116 252 5351, email: M.Makris@le.ac.uk. I am grateful to Elisabetta Iossa, Clare Leaver and Tim Besley for discussions and suggestions that have improved significantly this work. I would also like to thank the editor and two referees for very helpful comments that have improved the paper significantly. 


\section{Introduction}

Reforming public services has been and remains very high on the policy agenda for many developed countries. Examples of the recent debates over organisational forms and incentive schemes in public service provision are the so-called "Reinventing Government", "Modernising Government", and "New Public Management" approaches,${ }^{1}$ and the current policy discussions in UK, US and elsewhere. ${ }^{2}$

Some often posed questions are whethert there is scope for improvements in the performance of government organisations? If there is, should performance-pay be introduced, or how should public services/outputs and budget appropriations be linked, to enhance public service delivery? What are the efficiency properties of an optimally designed public organisation, or will production take place at minimum monetary costs and equate the sponsor's marginal willingness to pay with the marginal cost of public output? If not, how is the productivity of the agency related to the kind of the necessary inefficiencies? Should incentives be high-powered, or should the monetary rewards from exerting the appropriate level of effort and transmitting truthfully any required information be high?

The approaches mentioned above are based on the presumption that people care only about money and call for the introduction of private sector practices into the public sector, yet production of non-marketable, or collective, goods and services, whether by public bureaucracies, Non-Governmental Organisations (NGOs) that are given the task of providing public services, or public-benefit nonprofit organisations, is often mission-driven. For such organisations, ${ }^{3}$ agents may be influenced by attitudes, ideology, professional modes, or they may simply care about the amount and quality produced and their input. ${ }^{4}$ For instance, doctors and nurses take satisfaction from curing patients, academics take satisfaction in contributing

\footnotetext{
${ }^{1}$ See Osborne and Gaebler (1993) and Barzelay (2001).

${ }^{2}$ For some discussions on the current debate, see Burgess and Ratto (2003), Propper and Wilson (2003), Grout and Young (2003) and Grout and Stevens (2003). For a recent policy document on reforming public services see HM Treasury (2000).

${ }^{3}$ Hereafter, we will interchange the words (public) agency, agent(s) and agency's head.

${ }^{4}$ The non-pecuniary benefits that public agents derive from their output can also be thought of as a kind of intrinsic motivation. However, here these benefits do not depend explicitly on the extent of monetary incentives. For discussions of endogenous intrinsic motivation see Kreps (1997), Murdock (2002) and Benabou and Tirole
} (2003). 
to the advancement of knowledge, teachers take pleasure from producing good students, and aid-workers care about the successful provision of aid. ${ }^{5}$

In addition, especially in public and nonprofit organisations responsible for the production of non-marketable goods and services, agents can use only the resources which are made available to them by the sponsor(s) for production. That is, agents cannot use their own wealth for the production of the organisation's output. ${ }^{6}$

Therefore, the above literature may not always be well-suited for the study of the design of public and related organisations. Since mission-motivation and the presence of resource constraints seem relevant in organisations that provide collective goods and services, it is important to understand their interaction with performance-pay schemes and the implications for the optimal organisational design and provision of social services. For this reason, this paper contributes to the current debate by studying the optimal design of an agency which specialises in the provision of non-marketable, or collective, goods and services. ${ }^{7}$

Notice that this paper's analysis is not positive in nature, though it could give some alternative explanations for certain observations (see Section 6). We choose instead to contribute to the current debate by means of a normative analysis. In particular, we study the contract a principal should offer, in the presence of an administrative constraint to a motivated agent,${ }^{8}$ when the agent's motivation is common knowledge and the agent possesses superior information vis-a-vis the principal about his effort and/or productivity. The agent is a not-forprofit entity in that, as long as she is responsible for production, a balanced-budget increase in production is welfare enhancing for her. In other words, the agent values the output that she produces beyond the associated wage she earns. ${ }^{9}$ The administrative constraint requires

\footnotetext{
${ }^{5}$ See also Besley and Ghatak (2005). See Heckman et al. (1997), Burgess and Ratto (2003), Glazer (2004), Francois $(2000,2003$, and 2004) for discussions and evidence of intrinsic motivation in various nonprofit organisations. For a discussion of mission-motivation in government bureaucracies see Wilson (1989, p. 26). For an alternative model of endogenously determined missions in bureaucracies, see Dewatripont et al. (1999).

${ }^{6}$ See also Besley and Ghatak (2005) and Francois (2000 and2003).

${ }^{7}$ In the terminology of Horn (1995) we focus on administrative bureaus. For discussions of administrative bureaus, see Horn (1995, pp. 33, 40-43, 79-82, 170-172 and 180), Niskanen (1971, p. 24), Wilson (1989, p. 33), and Dixit (2002a).

${ }^{8}$ We use hereafter interchangeably the terms (intrinsically/mission/output) motivated agent and not-for-profit agent.

${ }^{9}$ Thus, intrinsic motivation arises here due to warm-glow altruism. See, for instance, Andreoni
} 
that all monetary costs of production must be born solely by the principal. In other words, the agent cannot use her own wealth for the provision of the non-marketable services.

In studying the optimal contract in question, we ask whether the efficiency properties of the workings of such an agency are compromised by its possessing private information about important determinants of the provision of services? If so, how should performance measures and budget appropriations be linked to enhance public service delivery? How are the possible inefficiencies related to the intrinsic motivation of the agent? How does the power of incentives depend on the output-motivation of the agent, or is intrinsic motivation a substitute for monetary incentives? Does output, for given productivity, increase with the mission-orientation of the agent?

Our analysis has important implications for the optimal design of public agencies, NGOs and, in general, nonprofit organisations which are responsible for the production of collective goods. Specifically, by answering the above questions, we demonstrate how the naive application of the private sector model to the public sector may worsen public service delivery. In more detail, we find that depending on the intensity of the non-pecuniary motive, the principal will either be able to implement the complete information contract or find it optimal to distort the performance of both the inefficient and the efficient agent! Furthermore, in the latter case, the principal may be able to ensure that no information rents are given to the agent (i.e. that service provision takes place at minimum monetary costs) regardless of the agent's productivity and even if public services are always provided. In addition, we find that the power of incentives is weakly decreasing with mission-motivation. In particular, incentives can be 'flat' even if the agent produces, regardless of her productivity, and even if the full-information outcome is not implementable. Finally, we find that higher output-motivation, while maintaining productivity, does not necessarily lead to an increase in public services. Though some of these findings may bear some similarities with certain results in the literature, as we discuss in the next Section, the above properties of an optimally designed organisation are largely different from many existing theoretical results.

Using these results, we are then also able to discuss, in Section 6, various issues in reforming provision of collective goods, like increasing competition and/or user-involvement,

(1988). For example, the relevance of such altruism is shown by the Olympic Games volunteers (see http://www.athens2004.com /en/Volunteers/ indexpage). 
the choice of an organisation's mission, bureaucratic conservatism and innovation. In many instances there, we explain how common policy proposals and common beliefs about the implications of incentives for the provision of social services may not be well-suited for organisations with the characteristics we emphasise in our study.

To understand the intuition behind our results, notice first that the administrative constraint gives rise to a limited-liability condition, which, in conjuction with the not-for-profit motivation of the agent, makes the agent's outside option inferior to any feasible employment offer by the principal. ${ }^{10}$ Under full information, then, the appropriate level of effort is exerted and transfers match minimum production costs. Moreover, production is such that the principal's marginal benefit equals the marginal production cost, which are both independent of the agent's motivation. Here, also, incentives are 'flat': there are no monetary rewards for 'good performance'.

Under asymmetric information, however, the above allocation may suffer from agency problems. Crucially, though, the administrative constraint limits the ability of the agent to deliver the required level of production when he over-reports his productivity. In addition, an increase in the not-for-profit orientation reduces the incentive to induce low production, so, if intrinsic motivation is sufficiently high, the agent cannot over-report and does not want to under-report productivity. If, however, mission-motivation is sufficiently low, the principal may need to offer information rents to the high-productivity agent to ensure 'good performance'. Due to the agent's intrinsic motivation, these rents depend on the performances of both the low- and the high- productivity agents. Therefore, reducing rents requires distorting production regardless of cost-type. Also, the availability of two instruments to reduce rents may also ensure that the agency can operate at zero rents. Moreover, due to the intrinsic motivation, the agent is more willing to perform well, which implies that the power of incentives can be zero even if the full-information outcome is not implementable. Finally, an increase in output-motivation may lead to lower production for low-productivity agencies. The reason is that motivation and output of the low-productivity agent are substitutes in the reduction of rents.

The organisation of the paper is as follows. Section 2 discusses the related literature, while Section 3 presents the model. Section 4 discusses some benchmark cases, while Section

\footnotetext{
${ }^{10}$ For an adverse selection problem with limited-liability constraints and the agent being only money-motivated, see Sappington (1983), and the treatment in Laffont and Martimort (2002, Ch. 3.5).
} 
5 solves for the optimal contract. Our results and their policy implications are discussed in Section 6. Section 7 concludes and points to directions for further research.

\section{Related Literature}

The theoretical apparatus used by the approaches mentioned in the Introduction is the principalagent paradigm, where, typically, one party, the principal, possesses all the bargaining power and the other party, the agent, is money-motivated and has superior information about important determinants of production such as the agent's effort and/or productivity. This model is used also by many existing studies of procurement and regulation, such as the ones in Baron and Myerson (1982), Laffont and Tirole (1993), Laffont and Martimort (2002) and elsewhere. ${ }^{11}$ The main message of this model is that when the outside option of the agent is not increasing very much with the agent's productivity and the agent's disutility from exerting effort is not very high, optimal organisation satisfies the following: if truthful transmission of information requires monetary incentives, then the low-productivity agent must be asked to produce below the full-information level. In addition, the high-productivity agent must be given information rents (in the form of a transfer/budget over and above the minimum monetary cost of production) as long as the low-productivity agent is asked to provide a positive level of output. Moreover, the high-productivity agent will be asked to produce the full-information level. Furthermore, if shirking is a concern then the agent will need to be given the appropriate monetary incentives to exert the appropriate level of effort. Also, if effort is productivity-enhancing then the agent will be asked to provide, given productivity, the full-information level of services. In addition, incentives must be high-powered. ${ }^{12}$ These findings are in contrast to the main results of our study mentioned in the Introduction.

Many applications of the principal-agent paradigm to public organisations emphasise also the possible multiplicity of an agency's principals, the multiplicity of tasks, measurement problems, the possible team-production elements and career concerns. ${ }^{13}$ In doing so, they inves-

\footnotetext{
${ }^{11}$ Note that the Baron and Myerson model, where the agent is money-motivated and there is no administrative constraint, is used also in Dixit (2002a) for the discussion of adverse selection problems in public service delivery.

${ }^{12}$ See, for instance, Laffont and Martimort (2002, Chs. 2, 4, 7.2).

${ }^{13}$ See, for instance, Rose-Ackerman (1986), Tirole (1994), Dewatripont et al. (1999), Burgess and Metcalfe (1999), Dixit (2002a). For a related discussion see also Bennett and Iossa (2005).
} 
tigate how the lessons of the standard principal-agent model have to be modified before being applied to the public sector. In most of this strand of research, however, profit-maximisation is still the maintained objective of the agency. In addition, agents are implicitly assumed to be able to use their own resources in order to manipulate the transmission of information to the $\operatorname{principal}(\mathrm{s}) \cdot{ }^{14}$

In this work, we abstract from issues of multiple tasks and/or career concerns and/or non-cooperation within the agency and/or within the decision-making body which is responsible for the agency's budget. We do not choose to do so because we believe that such issues are unimportant. Instead, we do so because we wish to focus on the implications for the design of mission-orientated organisations of the coexistence of intrinsic motivation and administrative constraint as a first step towards the study and understanding of more complicated environments.

Our paper is related to the work by Francois $(2000,2003$ and 2004) in that agents have a non-pecuniary motivation. However, there this motivation arises out of pure altruism and not due to 'warm glow' altruism. In the spirit of private provision of public goods, pure altruism leads to a free-riding problem in donations of labour. Moreover, there, outcome-based wages are not used. In fact, either moral hazard is not a problem, due to the on-spot verifiability of effort, or wages are flat with constant wages be "efficient" (i.e. above the market wage) whenever effort can be verified with a lag. Furthermore, information-eliciting monetary schemes are either not needed or not used. In Francois (2000 and 2003) emphasis is also placed on the lack of commitment on the part of the employer not to turn the agent's donated labour into profit when the employer is the residual claimant of any generated profits and can affect production after the donation of labour. Lack of commitment is not an issue here. Given these characteristics, these papers investigate when the power of incentives and/or 'efficiency wages' are lower in the nonprofit sector and/or when nonprofit organisations dominate for-profit firms in the provision of public goods. The main insight of these papers is that free-riding is less severe in public and non-profit organisations as, in these organisations, there is no residual claimant and hence the principal of such organisations is less inclined to make up for the agents' shirking.

\footnotetext{
${ }^{14}$ Notice here that Dixit (2002b) uses output-motivation in a multi-tasking model to discuss provision of social services. Dixit (1997) uses output-motivation in a multi-tasking and multi-principal model to discuss the power of incentives in public organisations. However, in both works, the agency relationship is not characterised by an administrative constraint.
} 
Our work is also related to Glazer (2004) and Besley and Ghatak (2005). They too assume that motivation arises due to 'warm glow' altruism and investigate the implications for collective production.

In Glazer (2004), the principal contributes also to the production. The focus there is on the possible lack of commitment on the part of the principal not to utilise the agent's donated labour merely to increase profits by means of adjusting his input after the agent has exerted her effort. It turns out that when the employer's input and the agent's effort are non-contractible, higher commitment may lead to lower output. This would be the case if the inputs are substitutes in the production of output and the worker's input is sufficiently less productive than capital (the employer's input). The first condition ensures that the outcome under commitment features higher effort and lower capital relative to the non-commitment outcome, while the second condition ensures that this will result in a net decrease in production. Here, instead, the principal does not supply any input, so no commitment issues arise.

In Besley and Ghatak (2005), output levels (for given productivity) are fixed. Thus, that work may not be well-suited for the study of organisations whose output can vary for given productivity. That work focuses, instead, on the matching of principals and agents visa-vis mission-orientation, and the effects on productivity and the power of incentives. Here, we investigate the effect of mission-motivation on production and associated monetary costs for given productivity. Furthermore our focus is on the short-run (i.e. on an environment where assortative matching between principals and agents has not yet taken place). Due to these differences in focus, one can view our work as complementary to theirs. In fact, some of our findings echo results in Besley and Ghatak (2005), including the substitutability between intrinsic and external incentives. Nevertheless, many of our results, such as the ones we emphasise above on the levels of production at optimum, also do not have counterparts there.

Finally, our work is also related to Delfgaauw and Dur (2008). There not all agents are mission-motivated, and intrinsic motivation and productivity are the agents' private information. Also, mission-motivated agents are by assumption high-productivity workers. Moreover, workers are not restricted by an administrative constraint. The question there is whether the principal finds it optimal to attract both motivated agents and profit-maximising-lowproductivity agents. The answer is affirmative. Also, it is shown that when the principal attracts both motivated and profit-maximising, but equally productive, agents, he implements 
distortions in the output of all workers. However, this result relies partly on the fact that the principal can choose the size of the workforce and partly on the fact that the principal minimises the production costs of a given level of public services. So, decreasing the profit-maximising agents' output to reduce the rents that are surrendered to the motivated agents in that set-up, requires an increase in the motivated agents' output to maintain total output. ${ }^{15}$ Our result, on the other hand, relies on the coexistence of mission-motivation and administrative constraints on the part of the single worker responsible for the production of an endogenous output.

\section{The Model}

Our model consists of an agent and her principal. The agency is the sole producer of a good valued only by the principal. The agency can be thought of as a group of citizens who have an expertise in the production of a non-marketable good, that is, in the attainment of the (public) agency's or the nonprofit organisation's mandated goal. The principal can be thought of as the decision-making body that has the authority of passing legislation for determining the interaction of the polity with the public bureau or as the board of stakeholders of a nonprofit organisation who are responsible for determining the budget of the agency and how it is linked with the organisation's performance.

In general, the non-marketable nature of the service may also imply the non-verifiability and thereby the non-contractibility of the agency's attained goals. It is crucial therefore to emphasise here, in order to avoid any misunderstandings, that what we refer hereafter to as an agency's output may differ from its mandated goal. In fact, as Baker (1992) and Heckman et al. (1997) among others emphasise, readily measured performance targets often substitute for the mandated goals of an agency, which are often non-verifiable. Such targets are what we refer, hereafter, to as the agency's (intermediate) output. ${ }^{16}$

\footnotetext{
${ }^{15}$ See, for more details, Delfgaauw and Dur (2008).

${ }^{16}$ The distinction we make here between an agency's mandated goal and (intermediate) output is essentially very similar to the distinction made in Wilson (1989, pp. 32-34) between a public bureau's 'goals' and '(critical) tasks' (see also HM Treasury 2000, p..2). The agencies we have in mind can in general be divided into what Wilson (1989) refers to as production and procedural organisations. For the former, the goal and the critical task coincide and can be verified (see Wilson 1989, pp. 35, 160-162, 244). In the case of procedural agencies, the mandated goal is not verifiable, but the critical task is (see Wilson 1989, pp. 320-323, 163-164, 202). As an example, tax and pensions administration bureaus are production agencies. Universities and bureaus
} 
Denote with $q$ the verifiable measure of the agent's performance (towards the attainment of the agency's mandated goal). Assume that $q \geq 0$. For the purposes of our model, the monetary cost (in terms of the numeraire good) of production of $q$ units of the agency's (intermediate) output is given by $C(q, \theta)=F+\theta q$, where $F \geq 0$ and $\theta>0$ are scalars. The fixed cost of production $F$ is common knowledge. ${ }^{17}$ The marginal cost of the agency's production (or the inverse of the agency's productivity) $\theta$ can take either of two values. In particular $\theta \in\left\{\theta_{1}, \theta_{2}\right\}$ with respective probabilities $s$ and $1-s$. These probabilities are common knowledge. Let $\Delta \theta \equiv \theta_{2}-\theta_{1}>0$. Thus, from the principal's point of view, $\theta_{2}-s \Delta \theta$ is the expected productivity of the agent.

In this paper we view the agent as a specialist in the production of the output. Specifically, we postulate that the likelihood of the marginal cost being low may depend on the 'effort' or 'managerial input' put by the agent, with more effort leading to lower expected marginal cost (or higher expected productivity). Thus, output may in general depend stochastically on effort through the effect of the latter on the productivity of the agency. Also, the effort may not be contractible. In addition, the agent may have superior information about productivity after effort has been exerted. ${ }^{18}$

In fact, we focus here on an environment where $\theta$ is private information of the agency. We also assume in the main text that the relationship between the principal and the agency is not hindered by moral hazard, so neither the realisation of the marginal cost of production nor the level of output, for given marginal cost, depends on some non-contractible activities of the agency. The reasons are the following. First, there are many public organisations where moral

that administer military procurement and the army during peacetime are, instead, examples of procedural organisations.

${ }^{17}$ Our results are qualitatively robust to allowing for a general cost function $C(q, \theta)$ with $C_{q}>0, C_{q q} \geq 0$, $C_{q \theta}>0$ and $C(0, \theta)=F$, where $F \geq 0$ is a scalar. Note our assumption that the fixed cost $F$ is common knowledge. This assumption avoids the emergence of multi-dimensional adverse selection and allows us to isolate the consequences for the optimal contract of the presence of the administrative constraint when the agent is a not-for-profit entity.

\footnotetext{
${ }^{18}$ The monetary cost of production $C(q, \theta)$ can also be thought of as being a reduced form of a more complicated model where, along the lines of Francois (2000, 2003, and 2004), lower-tier workers are paid "efficiency" or flat wages which are determined by the agency's head, with the productivity of the agency being stochastically dependent on the head's managerial effort to monitor the agency's workers.
} 
hazard is not a major problem, ${ }^{19}$ yet the agent may still have superior information over the true monetary costs of running the department. ${ }^{20}$ Second, as we show in Appendix C our results would be qualitatively valid for a large range of parameters even if moral hazard was the only concern $^{21}$ or in a 'hybrid' environment where the realisation of the marginal cost of production is the agent's private information and depends in a stochastic manner on non-contractible activities of the agent.

The principal derives a utility $B(q)$ from the agent's output, with $B(0)=0, B^{\prime}>0$, $B^{\prime}(0)>\theta_{2}, \lim _{q \rightarrow \infty} B^{\prime}(q)=0, B^{\prime \prime}<0$ and $B^{\prime \prime \prime}<0 .{ }^{22}$ Notice here that this representation of the principal's preferences can also capture an environment where $q$ is the intermediate output of the agency. To see this, suppose that $\tilde{B}(y)$ is the principal's utility over the agency's mandated goal $y$, and that this final output is given by $y=Y(q)$. Suppose now that $Y($.$) is$ known by both the principal and the agent, but non-verifiable by a third-party. Then, despite the fact that $y$ is non-contractible, the principal and the agent can 'calculate' $B(q) \equiv \tilde{B}(Y(q))$.

We follow the accounting convention that the principal bears up-front the fixed cost of setting up the agency. Therefore, fixed costs do not affect the decision of the agent to participate and transmit information. The utility on the part of the principal after having borne the fixed

\footnotetext{
${ }^{19}$ Wilson (1989) refers to these kinds of public organisation as agencies with standard operating procedures.
} The term standard operating procedures refers to the fact that bureaucratic slack for such agencies is not a major concern due to inputs-monitoring. In such organisations, the actions of the employees are observable and there are processes that pertain to the observable actions. Political principal(s) of such an agency can determine how allocations are related to certain standard operating procedures and possess a verifiable measure of the agency's performance. Examples of such public agencies are the army during peacetime, bureaus that administer (military) procurement and tax collection, and transfer agencies where most of expenditure is simply passing through (like agencies that administer pensions). For discussions on process-monitoring in public organisations, see Wilson (1989, pp. 35, 133, 159-164, 202, 221, 244, 320-323, 375), Prendergast (2003) and Dixit (2002). For a model of endogenous process monitoring see Novaes and Zingales (2003) and Francois (2003).

${ }^{20}$ See, for instance, Bendor et al. (1985) and Horn (1995, p. 87). As an example, civil servants in the Department of Defence often have superior knowledge on weapons systems and how they enhance military capability. Similarly, civil servants responsible for processing tax invoices and retirement benefits have better information on whether more (advanced or in number) computers will enable them to administer claims in a more efficient way.

\footnotetext{
${ }^{21}$ The interaction of output-motivation with moral hazard has been analysed by Francois (2000, 2003, and 2004) and Besley and Ghatak (2005).

${ }^{22}$ The latter assumption ensures a well-behaved optimisation problem on the part of the principal.
} 
cost is then defined by

$$
U_{p}(q, t)=B(q)-t
$$

where $t \geq 0$ is the budget allocated by the principal to the agency (i.e. the units of the composite good transferred to the agency). ${ }^{23}$ We also assume that the principal's wealth net of fixed costs is sufficiently high, so that he will not face any binding wealth constraints.

Define with $t-\theta q$ the agency's profits, appropriation or discretionary budget. This budget is a source of both pecuniary and non-pecuniary benefits for the agency: bureaucrats consume the discretionary budget in the form of both wages and perquisites. The agency also derives direct utility from providing $q$ units of the output. We capture this non-pecuniary motive by assuming that the agent maximises

$$
U(q, t ; \theta, a) \equiv a B(q)+t-\theta q,
$$

where $a>0$.

Crucially, $a B(q)$ is non-contractible. The parameter $a$ represents the extent of the agent's output-motivation that arises from 'warm glow altruism' relative to the marginal utility of the discretionary budget. ${ }^{24}$ Clearly then the case of $a \rightarrow \infty$ reflects an output-maximising agency, and, at the other extreme, the case of $a \rightarrow 0$ represents at the limit a profit-maximising agent. In the standard study of procurement and regulation it is assumed that $a=0 .{ }^{25}$ Note also that $a$ can also be thought of capturing, independent of monetary incentives, the quality of matching between the principal's and the agent's preferences in terms of the agency's goal. In other words, $a$ can be thought of representing the extent of the agency's sense of mission, along the lines of Wilson (1989, pp. 26, 95 etc). We refer hereafter to $a$ as the not-forprofit/mission/output/intrinsic motive of the agent. Assume that $a$ is common knowledge. ${ }^{26}$

\footnotetext{
${ }^{23}$ Qualitatively, our results are robust to allowing for a general welfare function on the part of the principal $U_{p}(q, t, \theta)$, with $U_{p}$ being concave with respect to $q$, decreasing with $t$ and $q_{1}^{o}>q_{2}^{o}$ where $q_{i}^{o}=\arg \max _{q}$ $U_{p}\left(q, \theta_{i} q, \theta_{i}\right)$.

${ }^{24}$ Notice that, in principle, there is nothing in our model thus far to preclude the case that $B(q)$ are the principal's profits. In fact, our model would also be compatible with an environment where $a B(q)$ are monetary returns on the part of the agents that, however, are non-contractible. This could, for instance, be the case if $a$ is observable but non-verifiable. I would like to thank Tim Besley for bringing this into my attention.

${ }^{25}$ As we will see later on, the limiting solution of our model with $a \rightarrow 0$ does correspond to the solution of the standard problem where $a=0$.

${ }^{26}$ An implicit assumption in most of the literature is that preferences of civil servants are common knowledge.
} 
Three important and related observations about the agent's preferences have to be made. First, the agent's welfare is not necessarily decreasing with output, as is the case in the canonical principal-agent model. Second, balanced-budget increases in production are welfare-enhancing for the agent, with the gain being increasing with the mission motivation $a$. Third, the marginal rate of substitution between output $q$ and budget appropriation $t$ is $B^{\prime}(q)$ for the principal and $\theta-a B^{\prime}(q)$ for the agent. Thus, the higher the output motivation $a$, the lower the compensation the principal needs to give to the agent for increasing production marginally, while keeping the agent's utility constant.

Let $t_{i}$ and $q_{i}$ be the budget appropriation and the required output if the marginal production cost is $\theta_{i}, i=1,2$. Any feasible relationship between the principal and the agent must satisfy certain constraints. First, we assume that the agent cannot be coerced by the principal to participate in some mechanism for the determination of some allocation. Accordingly, feasible allocations must leave the agency at least as well off as the agency's outside option. In this model the principal is the only buyer of the agency's 'expertise', and hence the agent's utility from taking up the outside option is equal to zero. ${ }^{27}$ To induce the agency to produce the output regardless of the underlying productivity, the following condition must be satisfied: ${ }^{28}$

$$
a B\left(q_{i}\right)+t_{i} \geq \theta_{i} q_{i}, \forall i \in\{1.2\}
$$

Second, we assume the presence of an administrative constraint: the budget cannot fall short of the monetary costs of production the agent faces. One of the implications of the administrative

The same is true for the preferences of the mission-motivated agents in Besley and Ghatak (2005). In principle, $a$ could also be private information on the part of the agency. However, in this paper the focus is on asymmetric information with respect to $\theta$. The reason is again to isolate the consequences for the optimal contract of the agency being characterised by an administrative constraint and being a not-for-profit entity. For a discussion of when productivity is common-knowledge but mission-motivation is the workers' private information, see Delfgaaw and Dur (2007).

${ }^{27}$ All that is needed for our results is that the reservation utility is sufficiently low. Again the reason for assuming zero reservation utilities is to isolate the consequences of administrative constraints in mission-orientated agencies.

${ }^{28}$ As it will become obvious shortly, our results are robust to assuming, instead, that $\theta$ is on-task rather than innate productivity and hence that the ex ante participation constraint $s\left[a B\left(q_{1}\right)+t_{1}-\theta_{1} q_{1}\right]+(1-s)\left[a B\left(q_{2}\right)+\right.$ $\left.t_{2}-\theta_{2} q_{2}\right] \geq 0$ must be satisfied. 
constraint is that the following limited-liability constraint must hold:

$$
t_{i} \geq \theta_{i} q_{i}, \forall i \in\{1.2\}
$$

Note that, due to $a>0$, the limited-liability constraint makes the participation constraint in (2) redundant. Hence we ignore in what follows the latter.

It is important for the understanding of our results to note that the administrative constraint is similar to, yet not the same as, a limited-liability constraint The reason is that the administrative constraint also affects the agent's ability to pretend she is of a different costtype, while the standard limited-liability does not affect the agent's opportunities to conceal convincingly her productivity (see for instance Sappington, 1986, and Laffont and Martimort, 2002, Ch 2). In more detail, note that, due to $t_{2} \geq \theta_{2} q_{2}$ and $\theta_{2}>\theta_{1}$, any allocation intended for the inefficient agent can also be administered by the low marginal cost agent (i.e. $t_{2}>\theta_{1} q_{2}$ ). Crucially, however, the reverse may not be true: $t_{1}<\theta_{2} q_{1}$ can in principle be the case, which implies, given the administrative constraint $t_{1} \geq \theta_{1} q_{1}$, that a high-cost agency will not be able to execute the allocation $\left\{t_{1}, q_{1}\right\}$.

Assuming the existence of a perfect and benevolent device which ensures the enforcement of contracts, we have by the revelation principle ${ }^{29}$ that the principal cannot do better than offering a direct revelation mechanism. Under such a mechanism, incentive-compatibility conditions must be satisfied, ${ }^{30}$ yet the administrative constraint lalso limits the opportunities for under-reporting costs, since (recall from above) it may be the case that $t_{1}<\theta_{2} q_{1}$. Thus, incentive-compatibility requires here that the agent of a certain cost-type has no incentive to choose a contract that he can administer and is intended for producers of a different type. That is,

$$
\begin{aligned}
& a B\left(q_{1}\right)+t_{1}-\theta_{1} q_{1} \geq a B\left(q_{2}\right)+t_{2}-\theta_{1} q_{2} \text { and } \\
& a B\left(q_{2}\right)+t_{2}-\theta_{2} q_{2} \geq a B\left(q_{1}\right)+t_{1}-\theta_{2} q_{1} \text { when } t_{1} \geq \theta_{2} q_{1} .
\end{aligned}
$$

To re-emphasise the difference between a limited-liability and an administrative constraint, note that under the former and in the absence of the latter, (5) would have been replaced by the more stringent condition $a B\left(q_{2}\right)+t_{2}-\theta_{2} q_{2} \geq a B\left(q_{1}\right)+t_{1}-\theta_{2} q_{1}$.

\footnotetext{
${ }^{29}$ See, for instance, Mas-Colell et al. (1995, Ch. 23).

${ }^{30}$ Note that we restrict our analysis to the case of deterministic contracts. This can be motivated by postulating that stochastic allocation rules are hard to be enforced by a court of law.
} 
Let $\pi_{i} \equiv t_{i}-\theta_{i} q_{i}, i=1,2$, be the type- $\theta_{i}$ agent's information rents. Using the definition of information rents to eliminate $t_{i}$, we have that the principal's problem is to maximise $E_{\theta_{i}}\left[B\left(q_{i}\right)-\theta_{i} q_{i}-\pi_{i}\right]$ with respect to $\left\{\pi_{i}, q_{i}\right\}_{i \in\{1,2\}}$ subject to $q_{i} \geq 0, i=1,2$, the incentivecompatibility constraints

$$
\begin{aligned}
& \pi_{1} \geq \pi_{2}+\Delta \theta q_{2}-a\left[B\left(q_{1}\right)-B\left(q_{2}\right)\right] \\
& \pi_{2} \geq \pi_{1}-\Delta \theta q_{1}+a\left[B\left(q_{1}\right)-B\left(q_{2}\right)\right] \text { when } \pi_{1} \geq \Delta \theta q_{1},
\end{aligned}
$$

and the limited-liability constraints

$$
\begin{aligned}
& \pi_{1} \geq 0 \\
& \pi_{2} \geq 0 .
\end{aligned}
$$

We turn to the solution of this problem after we analyse some useful benchmark cases.

\section{Benchmark Cases}

Before we investigate the solution to the above problem we examine four benchmark cases. The analysis of these cases will help the understanding of the forthcoming results and emphasise that they rely critically on the coexistence of mission-motivation and the administrative constraint. We start by finding the optimal allocations when information is symmetric. These allocations are denoted with the superscript $o$. When information is symmetric, the incentivecompatibility constraints (6) and (7) are irrelevant. Thus, the principal is restricted only by the administrative constraints (8)and (9). It follows in a straightforward manner that the principal is better off by leaving no 'excess budget' (information rents) to the agency (i.e. $t_{i}^{o}=\theta_{i} q_{i}^{o}$ for any $i \in(1,2))$. Also, the level of output $q_{i}^{o}$ satisfies:

$$
B^{\prime}\left(q_{i}^{o}\right)=\theta_{i}, \forall i \in\{1,2\}
$$

Note that $q_{1}^{o}>q_{2}^{o}>0$. We refer to these allocations as the full-information contract and $q^{o}$ as the efficient (from the principal's point of view) level of production. For a given marginal cost of production $\theta$, the principal will indeed offer the contract in question to the agency and output will be produced if the net value of public service delivery $B\left(q_{i}^{o}\right)-\left(\theta_{i} q_{i}^{o}+F\right)$ is non-negative. Assume that

$$
B\left(q_{2}^{o}\right)-\left(\theta_{2} q_{2}^{o}+F\right) \geq 0
$$


This ensures that the agency is set up under complete information.

Next, we consider the case the agent is a profit-maximising entity (i.e. $a=0$ ) and can pretend to be of any cost-type regardless of the associated allocation. Here, the incentivecompatibility constraints (6) and (7) reduce to $\pi_{j} \geq \pi_{k}+\left(\theta_{k}-\theta_{j}\right) q_{k}, j, k=1,2, j \neq k$. The principal's problem is then $\max _{\left\{\pi_{i} q_{i}\right\}_{i=1,2}}\left\{s\left[B\left(q_{1}\right)-\theta q_{1}-\pi_{1}\right]+(1-s)\left[B\left(q_{2}\right)-\theta q_{2}-\pi_{2}\right]\right.$ s.t. $\pi_{j} \geq \pi_{k}+\left(\theta_{k}-\theta_{j}\right) q_{k}$ and $\left.\pi_{i} \geq 0, q_{i} \geq 0, i, j, k=1,2, j \neq k\right\}$. As is well-known, in this case the inefficient agency attains utility equal to that under its outside option (i.e. $\pi_{2}=0$ ) while the efficient agency is given just enough utility to prevent it from claiming that it is inefficient (i.e. $\pi_{1}=\Delta \theta q_{2}$ ). In addition, the efficient agent would produce $q_{1}^{o}$, while the inefficient agent would produce $\max \left\{0, B^{\prime-1}\left(\theta_{2}+\frac{s}{1-s} \Delta \theta\right)\right\}<q_{2}^{o}$. The high-cost agent's output strikes a balance between distorting downwards its production and reducing the low-cost agent's information rents. ${ }^{31}$ Notice also that here the power of incentives (i.e. the reward from reporting truthfully that productivity is high) is $\pi_{1}-\pi_{2}=\Delta \theta q_{2}$. Assume, hereafter, that a profit-maximising entity is never shut-down. That is, $q_{2}>0 .{ }^{32}$

Suppose now that there were no administrative constraint, but $a>0$. An increase in the intrinsic motivation leads to a preference for higher production, so if $q_{1}>q_{2}$, then the high-productivity agent has a lower incentive to over-report costs, while the low-productivity agent has a higher incentive to under-report costs. One might expect that this could lead to qualitatively different incentives to the ones above. However, this is not the case. Let $U_{i} \equiv \pi_{i}+a B\left(q_{i}\right)$ be the agent's utility. Then, the incentive-compatibility constraints would be $U_{j} \geq U_{k}+\left(\theta_{k}-\theta_{j}\right) q_{k}, k, j, 1,2, k \neq j$, and the participation constraints $U_{i} \geq 0$ would be relevant. The principal's net surplus could be rewritten as $(1+a) B(q)-\theta q-U \equiv S(q ; a)-$ $\theta q-U$. Thus, the principal's problem would be equivalent to the textbook model of adverse selection above. In particular, one would only need to replace $B($.$) with S($.$) , and \pi$ with $U$. Thus, it is still the case that the low-productivity agent's production is distorted downwards to reduce the utility rents, $U_{1}=\Delta \theta$, of the high-productivity agent who produces at the fullinformation level. Also, the low-productivity agent is given zero rents, $U_{2}=0$. Due to intrinsic motivation, the latter implies a negative net monetary transfer $\pi_{2}=-a B\left(q_{2}\right)<0$, which captures the 'donated labour' of the agent. Investigating this case in more detail could be of

\footnotetext{
${ }^{31}$ See, for instance, Laffont and Martimort (2002, Ch. 2) for more details.

${ }^{32}$ In general, if $s$ is high enough shut-down may be optimal.
} 
interest for certain cases of public services. However, it is out of the scope of the present work, where we take the view that wealth-constraints are an important characteristic of many service providers. It is worth noticing, however, in passing that in this benchmark case output would be increasing with the not-for-profit motive, regardless of productivity and whether information about productivity is symmetric or not.

Finally, if the administrative constraint were present and $a=0$, then the predictions would effectively be the ones of the canonical paradigm. The reason is very simple: with no output-motivation (i.e. $a=0$ ) feasibility of mis-reporting only relaxes the inefficient producer's incentive-compatibility constraint (vis-a-vis the canonical model) which is redundant anyway in designing the optimal contract.

\section{The Optimal Agency}

We now turn to the main focus of our work: the derivation of the optimal contract when the agent is both output-motivated and wealth-constrained. Compared to the problem when the agent is a profit-maximising entity and there is no administrative constraint, we have that the minimum information rents that ensure participation are still equal to zero. Nevertheless, our problem here is not a standard adverse selection problem. The reason is twofold. First, due to the administrative constraint, the producer is, in effect, wealth-constrained, and thereby the high-cost incentive-compatibility constraint is less stringent, all other things equal, in the sense that if $\pi_{1}<\Delta \theta q_{1}$, then the high-cost agent cannot under-report her costs. ${ }^{33}$ Second, conditional on mis-reporting costs being feasible (i.e. $\pi_{1} \geq \Delta \theta q_{1}$ ) and $q_{1}>q_{2}$, missionmotivation (i.e. $a>0$ ) makes under-reporting costs more attractive and, crucially for our purposes, over-reporting costs less attractive. That is, the low-cost (resp. high-cost) incentivecompatibility constraint is relaxed (resp. becomes more stringent). The stronger these effects are, the higher the mission-motivation is. This is a direct consequence of the fact that for any given information rents, $\pi$, the agent values output directly by $a B(q)$.

In what follows, let us denote with $\left(\pi_{i}^{*}(a), q_{i}^{*}(a)\right), i=1,2$, the optimal contract offered to the agency, given the utility parameter $a \cdot{ }^{34}$ Consider now the full-information contract. Under this contract $\pi_{1}^{o}=0<\Delta \theta q_{1}^{o}$, and thereby the less productive agent cannot claim that she

\footnotetext{
${ }^{33}$ See also, for instance, Che and Gale (2000).

${ }^{34}$ We suppress the obvious dependence of the optimal contract on $s$.
} 
is more productive. Also, $\pi_{2}^{o}=0$ and $q_{1}^{o}>q_{2}^{o}$. Thus, the low-cost agency has no incentive to over-report costs if $a \geq \frac{\Delta \theta q_{2}^{o}}{B\left(q_{1}^{o}\right)-B\left(q_{2}^{o}\right)} \equiv a^{o}>0$ and the full-information contract can be implemented.

We thus have

Proposition 1 (The Efficient Regime) If $a \geq a^{o}$ we have that $q_{i}^{*}(a)=q_{i}^{o}$ and $t_{i}^{*}(a)=\theta_{i} q_{i}^{*}(a)$, for any $i=1,2$.

Thus, if the not-for-profit motive of the agent is high enough, the exchange relationship between the principal and the output-provider will be efficient, even if the productivity of the agency is its private information. That is, the efficiency properties of the workings of the agency are not compromised.

Turn now to the case of $a<a^{o}$. In this case, the output-motivation of the agent is sufficiently low so that the incentive to over-report costs, in order to achieve an increase in profits by $\Delta \theta q_{2}^{o}$, dominates the incentive to produce a high level of output due to mission motivation. Clearly, then the optimal contract $\left\{\pi_{i}^{*}(a), q_{i}^{*}(a)\right\}_{i \in\{1,2\}}$ will differ from the fullinformation contract.

Recall our assumption from Section 4 that a profit-maximising agency would never be shut-down. This implies that the agency is set up regardless of its mission-motivation and regardless of its cost-type. ${ }^{35}$ In presenting the corresponding optimum mechanism it will prove useful to employ the following definitions:

$$
\begin{aligned}
\hat{q}_{i}(a), \text { for any } i & =1,2 \text {, are defined by } \\
B^{\prime}\left(\hat{q}_{1}(a)\right) & =\theta_{1} /(1+a) \text { and } \\
\hat{q}_{2}(a) & =\arg \max _{q \geq 0}\left\{[1-s(1+a)] B(q)-\theta_{2} q\left[1-s+s \frac{\Delta \theta}{\theta_{2}}\right]\right\}, \\
\bar{q}_{i}(a)> & 0, \text { for any } i=1,2, \text { are defined by the solution of the system } \\
\frac{a B^{\prime}\left(\bar{q}_{1}(a)\right)}{a B^{\prime}\left(\bar{q}_{2}(a)\right)+\Delta \theta}= & -\frac{s\left[B^{\prime}\left(\bar{q}_{1}(a)\right)-\theta_{1}\right]}{(1-s)\left[B^{\prime}\left(\bar{q}_{2}(a)\right)-\theta_{2}\right]} \text { and } \\
a B\left(\bar{q}_{2}(a)\right)+\Delta \theta \bar{q}_{2}(a) & =a B\left(\bar{q}_{1}(a)\right) .
\end{aligned}
$$

\footnotetext{
${ }^{35}$ A straightforward application of the envelope theorem implies that, as was expected, under no shut-down higher motivation is always beneficial for the principal if $a<a^{o}$. Also, if the high-cost agency is shut down the low-cost agent is efficient, and hence the principal's payoff is, crucially, independent of the agent's motivation. Moreover, as we will see shortly, as $a \rightarrow 0$ the optimal no shut-down contract approximates the corresponding contract under $a=0$. These observations imply, directly, that if a profit-maximising agency operates regardless of its productivity, so does an intrinsically motivated agent.
} 
It turns out that when we examine the optimal mechanism we can ignore the incentivecompatibility constraint for the high-cost agency (7). As in the typical model, this constraint is satisfied ex post. We can also ignore the constraint $q_{1}(a) \geq 0$. In addition, we have that the lowcost agency's incentive compatibility constraint is binding. Also binding is the high-cost agent's limited-liability constraint. ${ }^{36}$ Thus the optimal contract is given by $\left\{\pi_{i}^{N}(a), q_{i}^{N}(a)\right\}_{i \in\{1,2\}}$ with $\pi_{2}^{N}(a)=0, \pi_{1}^{N}(a)=\pi_{2}^{N}(a)-a\left[B\left(q_{1}^{N}\right)-B\left(q_{2}^{N}\right)\right]+\Delta \theta q_{2}^{N}(a)$, and $q_{i}^{N}(a)$, for any $i=1,2$, maximising

$$
s\left[(1+a) B\left(q_{1}\right)-\left(a B\left(q_{2}\right)+\Delta \theta q_{2}+\theta_{1} q_{1}\right)\right]+(1-s)\left[B\left(q_{2}\right)-\theta_{2} q_{2}\right]
$$

subject to

$$
\begin{aligned}
q_{2} & \geq 0 \text { and } \\
a B\left(q_{2}\right)+\Delta \theta q_{2} & \geq a B\left(q_{1}\right) .
\end{aligned}
$$

Note that the latter constraint is nothing else but the limited-liability constraint for the low-cost agency, when (a) this agency is indifferent between the contract designed for it and the contract designed for the high-cost agent, and (b) the high-cost agency's limited-liability constraint is binding. It follows that production under this scheme is given by ${ }^{37}$

$$
q_{i}^{N}(a)=\hat{q}_{i}(a)>0, \text { for any } i=1,2, \text { if } a B\left(\hat{q}_{2}(a)\right)+\Delta \theta \hat{q}_{2}(a) \geq a B\left(\hat{q}_{1}(a)\right)
$$

or

$$
q_{i}^{N}(a)=\bar{q}_{i}(a), \text { for any } i=1,2 \text {, if } a B\left(\hat{q}_{2}(a)\right)+\Delta \theta \hat{q}_{2}(a)<a B\left(\hat{q}_{1}(a)\right)
$$

Accordingly, with this scheme, production is strictly positive regardless of the agent's cost-type, and output is increasing with the agent's productivity (i.e. $\left.q_{1}^{N}(a)>q_{2}^{N}(a)\right)$. ${ }^{38}$ More interestingly, output distortions occur regardless of the agent's type. In particular, we have in a straightforward manner from $a<a^{o}$, conditions (15) and (16) and the definitions of $\hat{q}_{i}(a)$ and $\bar{q}_{i}(a) i=1,2$, that $0<q_{2}^{N}(a)<q_{2}^{o}<q_{1}^{o}<q_{1}^{N}(a)$. That is, the high-cost agency undersupplies and the low-cost agency oversupplies the valued services. In addition, as expected,

\footnotetext{
${ }^{36}$ See Appendix A for more details.

${ }^{37}$ See Appendix B for the derivation.

${ }^{38}$ Note that under this solution we have that $\pi_{1}^{N}(a)-\Delta \theta q_{1}^{N}(a)=a\left[B\left(q_{2}^{N}(a)\right)-B\left(q_{1}^{N}(a)\right)\right]+\Delta \theta\left(q_{2}^{N}(a)-q_{1}^{N}(a)\right)$ $<0$ and $\pi_{2}^{N}(a)-\pi_{1}^{N}(a)+\Delta \theta q_{1}^{N}(a)-a\left[B\left(q_{1}^{N}(a)\right)-B\left(q_{2}^{N}(a)\right)\right]=\Delta \theta\left(q_{1}^{N}(a)-q_{2}^{N}(a)\right)>0$, and thus the high-cost agency does not find it either feasible or optimal to mis-report its cost-type.
} 
problems of excess production cost may arise. The reason is that now the low-cost agency's limited-liability constraint may be slack (i.e. the low-cost agency may enjoy information rents). This will be the case if and only if $a B\left(\hat{q}_{2}(a)\right)+\Delta \theta \hat{q}_{2}(a)>a B\left(\hat{q}_{1}(a)\right)$, or, after re-arranging, $a \in\left(0, \frac{\Delta \theta \hat{q}_{2}(a)}{B\left(\hat{q}_{1}(a)\right)-B\left(\hat{q}_{2}(a)\right)}\right)$, yet in contrast to the case when the agent is not output-motivated, the low-cost agency may also produce at minimum cost despite the high-cost agency's output being positive. This occurs when $a \geq \frac{\Delta \theta \hat{q}_{2}(a)}{B\left(\hat{q}_{1}(a)\right)-B\left(\hat{q}_{2}(a)\right)}$.

To understand the above contract, ${ }^{39}$ recall that if $a<a^{o}$ the low-cost agency, when offered the full-information contract, does have an incentive to over-report costs. As in the canonical model, then we have that the less-productive agency is given no information rents, $\pi_{2}=0$. Also, the low-cost agent's incentive-compatibility constraint is binding, and the principal distorts downwards the production of the high-cost agent to decrease the information rents of the more productive agent. However, here, due to the agent being output-motivated, information rents can also be reduced by distorting upwards the production of the low-cost agent. To see this, note that a binding low-cost incentive-compatibility constraint implies that $\pi_{1}=\Delta \theta q_{2}$ - $a\left[B\left(q_{1}\right)-B\left(q_{2}\right)\right] \equiv \pi\left(q_{1}, q_{2}, a, \Delta \theta\right)$, so (non-negative) information rents $\pi\left(q_{1}, q_{2}, a, \Delta \theta\right)$ are decreasing with $q_{1}$, as well as increasing with $q_{2}$. Thus, the principal has an incentive to decrease the output of the high-cost agent and increase the output of the low-cost agent. The optimal production levels strike a balance between distortions and excessive production costs by the lowcost agency, as in the canonical model. In fact, note that problem (14), which gives the solution $q_{i}^{N}(a) i=1,2$, can be written as $\max _{q_{i} \geq 0}\left\{s\left[B\left(q_{1}\right)-\theta_{1} q_{1}-\pi\left(q_{1}, q_{2}, a, \Delta \theta\right)\right]+(1-s)\left[B\left(q_{2}\right)-\theta_{2} q_{2}\right]\right.$ s.t. $\left.\pi\left(q_{1}, q_{2}, a, \Delta \theta\right) \geq 0\right\}$. Finally, the fact that the principal has two (distorting) instruments may enable him to expropriate all rents, even if the high-cost agent's output is positive.

We refer to the above mechanism (irrespective of the existence of rents) as the No-ShutDown Regime/Contract. It follows then directly that

Proposition 2 (The Second-Best Regime) If $a<a^{o}$, the second-best contract is the No-Shut-Down contract.

To summarise our discussion thus far, let us identify the following cases, depending on

\footnotetext{
${ }^{39}$ Taking the limit of the solution of our model as $a \rightarrow 0$ we find that our solution approximates the solution of the standard adverse selection problem. To see this define $q_{i}^{N}(0) \equiv \lim _{a \rightarrow 0} q_{i}^{N}(a)$ for any $i=1,2$, and observe that as $a \rightarrow 0$ we have $a\left[B\left(\hat{q}_{2}(a)\right)-B\left(\hat{q}_{1}(a)\right)\right]+\Delta \theta \hat{q}_{2}(a) \geq 0$. Hence note from $(15)$ and $(16)$ that $q_{1}^{N}(0)=q_{1}^{o}>q_{2}^{o}$ $>q_{2}^{N}(0)=\min \left\{0, B^{\prime-1}\left(\theta_{2}+\frac{s}{1-s} \Delta \theta\right)\right\}$. Finally, we have that the high-cost agent operates at minimum cost and the low-cost agency enjoys information rents equal to $\Delta \theta q_{2}^{N}(0)$.
} 
the strength of the intrinsic motive. First we have the efficient regime. This occurs if and only if $a \geq a^{o}$. In this case, the agency produces the full-information level of output at minimum cost, regardless of its productivity.

Then, we have the second-best regime. This regime occurs if and only if the not-forprofit motive is sufficiently low, $a<a^{o}$. Now, the low-productivity agency under-produces, while the high-productivity agency over-produces. Also, the low-productivity agency is always productively efficient (i.e. never enjoys information rents) while the high-productivity provider may or may not be productively efficient. Specifically, the production plan $\left\{q_{1}^{*}(a), q_{2}^{*}(a)\right\}$ will be such that $0<q_{2}^{*}(a)=q_{2}^{N}(a)<q_{2}^{o}<q_{1}^{o}<q_{1}^{*}(a)=q_{1}^{N}(a)$. Also, the low-cost agent will enjoy rents if and only if the not-for-profit motive is very low (i.e. $\left.a \in\left[0, \frac{\Delta \theta \hat{q}_{2}(a)}{B\left(\hat{q}_{1}(a)\right)-B\left(\hat{q}_{2}(a)\right)}\right)\right)$.

Our results are in striking contrast to those of the canonical model. First, if $a \geq a^{o}$, then the agency operates under the full-information contract regardless of its cost-type. Second, if $a<a^{o}$, then the low-cost agency over-produces and it can be productively efficient even if the high-cost agent produces a positive level. Clearly, then, using the lessons from the canonical principal-agent model in the design of collective-goods provision may be a misguided reform agenda.

\section{Discussion of Results}

Recall that when output-motivation is sufficiently high (i.e. $a \geq a^{o}$ ) then provision of collective goods is efficient from the principal's point of view. This implies that output is independent of the intrinsic motivation. The reason is that the principal's net surplus from the provision of collective goods is independent of the agent's intrinsic motivation.

In the canonical model (i.e. without motivation and administrative constraint) competition between agents for the right to produce the output valued by the principal can be beneficial. In more detail, if the principal is faced with a pool of agents, then it is more likely for low-cost agents to emerge. Also, given a single, incentive-compatible and individually-rational job opening, agents would self-select themselves. That is, high-cost agents would choose the $\left\{t_{2}, q_{2}\right\}$ sub-contract and the low-cost agents would select the $\left\{t_{1}, q_{1}\right\}$ terms of employment. ${ }^{40}$ In this environment, the principal would have appointed a low-cost agent, if present, to ensure a higher net surplus. It is interesting to note that in our set-up we arrive at an additional

\footnotetext{
${ }^{40}$ For a related discussion of a similar point see Hoxby (1999).
} 
channel through which competition may be beneficial. Specifically, if the polity is faced with a pool of 'experts' for the provision of public services, who all have the same cost-type which is nevertheless unknown to the (political) principal, then the principal would have appointed an agency which is characterised by sufficiently high motivation (i.e. $a \geq a^{o}$ ) to ensure efficient provision of public services. Therefore, introducing competition at the supply-side of the provision of collective goods will improve the efficiency properties of the workings of an agency by making it more likely that agents with high intrinsic motivation emerge. ${ }^{41}$

Let us turn to the case of distorted production (i.e. $a<a^{o}$ ). We find that low-productivity agencies under-produce, while high-productivity agencies over-produce. To understand the relevance of this result, note that popular accounts of public bureaucracy view the latter as highly inefficient and the reason for oversized public sectors. Also, this perspective has often been used as an argument in favour of privatisation and introduction of competition in public services. The most influential scholarly support to such views can, arguably, be found in Niskanen (1971). The paradigm of empire-building bureaucrats has been largely discounted in the much celebrated work of Wilson (1989). ${ }^{42}$ Specifically, using a number of case studies, Wilson argues that many of the popular accounts of overextended bureaucracies are often driven by common misperceptions. He provides examples of large agencies but also counter-examples of many underproviding bureaus. Interestingly, then, our results on the production levels are consistent with many case-studies in Wilson. Though there may as well be other alternative explanations to these observations, the one given by our study is that low-productivity agencies underproduce and high-productivity agencies overproduce, and both directions of inefficient provision are part of the optimal organisational design as a response to the information problems encountered by the principals of these agencies.

A common belief in the recent debates over reforming public services is that the higher the intrinsic motivation of service providers or the higher the sense of mission within agencies, the higher the level of provision. A typical example of such arguments is Wilson (1989). In that work (p. 95), a 'culture that is widely shared and warmly endorsed by operators and

\footnotetext{
${ }^{41}$ For related discussions on how politicians decide which agencies to create see, for instance, McCubbins (1985), Calvert et al. (1989) and Banks and Weingast (1992). See also Besley and Ghatak (2005) for a related discussion which emphasises the importance of higher diversity in allowing for better matching, in terms of mission-preference, between principals and agents.

${ }^{42}$ See Ch 7 and pp. 180-181.
} 
managers alike' is viewed as 'the chief way' to induce good performance (see also, for instance, pp. 98, 100, 101, 108, 109 and 110). In terms of our model, this would be reflected in $a$ and output being positively related. However, as we show below, this is not necessarily a feature of an optimally designed bureau. In fact, our study emphasises that in certain cases, optimal organisational design implies that output increases with higher mission-motivation, and in other cases, provision of social services will decrease as a result of higher intrinsic motivation. The reason is simple. The common perception is correct when mission-motivation and level of provision are viewed in isolation from monetary incentives. However, when intrinsic and explicit incentives are analysed jointly, then this common belief may be misguided.

To get a closer look at how levels of provision depend on the not-for-profit motive, consider, first, the case of the low-cost agency enjoying information rents. Recall that in this case $q_{i}^{N}(a)=\hat{q}_{i}(a)>0, i=1,2$. Clearly then a marginal increase in the not-for-profit motive will increase the low-cost agency's output while decreasing the less productive agency's production. To understand this, recall that in this case the principal surrender information rents, which are equal to $\pi\left(q_{1}, q_{2}, a, \Delta \theta\right)=\Delta \theta q_{2}-a\left[B\left(q_{1}\right)-B\left(q_{2}\right)\right]$. Note then that $\frac{\partial^{2} \pi}{\partial a \partial q_{1}}=$ $-B^{\prime}\left(q_{1}\right)$ and that $\frac{\partial^{2} \pi_{1}}{\partial a \partial q^{2}}=B^{\prime}\left(q_{2}\right)$. Thus, and after recalling that $q_{1}>q_{2}$, motivation and output of the high-productivity agent are complements while output-orientation and output of the high-cost agent are substitutes in the reduction of excessive monetary production costs. Therefore, higher mission-motivation leads the principal to reduce by more the output of the high-cost agent and increase by more the high-productivity agent's output.

Let us turn our attention now to the case of the agency being productively efficient, regardless of its cost-type. In this case, the effect of a higher not-for-profit motive on the output of the agency is ambiguous. To see this, recall first that an increase in the mission-motivation, $a$, results in a decrease of the information rents, all other things equal. Also, rents are increasing (resp. decreasing) with the production level of the least (resp. most) productive agent. Thus, if, at optimum, the agent is not left any rents, as would be the case if he was productively efficient, then limited-liability implies that an increase in mission-motivation requires an increase in the production of the least productive agent and/or a decrease in the production of the more productive agent. However, these effects will be counteracted by the fact that, as we have seen immediately above, intrinsic motivation and output of the high-productivity agent are complements while mission-orientation and output of the high-cost agent are substitutes in the reduction of excessive monetary production costs. Therefore, the net effect of higher mission- 
motivation on the output of a productively efficient bureau will depend on the balance of these opposing effects.

Therefore, in contrast to common belief, developing a user-orientated culture in the provision of collective goods will not necessarily increase the level of provision. Interestingly, note that this may be true regardless of production costs. This counter-intuitive implication for the optimal design of organisations that provide social services follows, as we have seen above, from the interaction of monetary incentives and intrinsic motivation. Our result that the effect of mission-motivation on output is ambiguous echoes that of Glazer (2004) in a different context. Here, the principal does not contribute any real input into the production, while in Glazer the principal's and agent's inputs are substitutes and the principal can commit on the level of his input prior to the agent contributing hers.

Next, we discuss the power of incentives. The power of incentives is defined here as the difference $\left[t_{1}^{*}(a)-\theta_{1} q_{1}^{*}(a)\right]-\left[t_{2}^{*}(a)-\theta_{2} q_{2}^{*}(a)\right] \equiv P(a)$. Thus, the power of incentives in a missionorientated organisation with administrative constraint is equal to $\pi_{1}^{*}(a)-\pi_{2}^{*}(a)$. Therefore, if $a \geq a^{o}$ we have that $P(a)=0$, while if $a<a^{o}$, then the power of incentives is $P(a)=$ $\Delta \theta q_{2}^{N}(a)-a\left[B\left(q_{1}^{N}(a)\right)-B\left(q_{2}^{N}(a)\right)\right]$. Recall that $q_{1}^{N}(a)>q_{1}^{o}>q_{2}^{o}>q_{2}^{N}(a)$ and $a\left[B\left(q_{1}^{N}(a)\right)-\right.$ $\left.B\left(q_{2}^{N}(a)\right)\right] \leq \Delta \theta q_{2}^{N}(a)$. Clearly, then, the power of incentives under the full-information contract is (weakly) lower than that under the No-Shut-Down contract. In fact, notice that if $a<a^{o}$ then $P(a)=\pi\left(q_{1}^{N}(a), q_{2}^{N}(a), a, \Delta \theta\right)$. That is, the power of incentives coincides with the size of rents given to the high-productivity agent. Thus, if $a \in\left(0, \frac{\Delta \theta \hat{q}_{2}(a)}{B\left(\hat{q}_{1}(a)\right)-B\left(\hat{q}_{2}(a)\right)}\right)$, incentives are not 'flat', yet within this range, the power of incentives and mission-motivation are substitutes (i.e. $\left.P^{\prime}<0\right)$. To see this, recall that if $a \in\left(0, \frac{\Delta \theta \hat{q}_{2}(a)}{B\left(\hat{q}_{1}(a)\right)-B\left(\hat{q}_{2}(a)\right)}\right)$, then $q_{i}=\hat{q}_{i}(a), i=1,2$, $\pi\left(q_{1}, q_{2}, a, \Delta \theta\right)=\Delta \theta q_{2}-a\left[B\left(q_{1}\right)-B\left(q_{2}\right)\right]$ and $\hat{q}_{1}^{\prime}(a)>0, \hat{q}_{2}^{\prime}(a)<0$. It follows that the power of incentives here is lower than in a profit-maximising agency (i.e. than $P(0)$ ). This is consistent with, and complements, Besley and Ghatak (2005) and Francois (2000, 2003 and 2004). It also complements arguments like the ones in Dixit (2002a) that are based on multi-tasking and common-agency as to why public organisations tend to rely less than private organisations on monetary incentives. Recall, however, that if $a \in\left[\frac{\Delta \theta \hat{q}_{2}(a)}{B\left(\hat{q}_{1}(a)\right)-B\left(\hat{q}_{2}(a)\right)}, a^{o}\right)$ then rents are zero, so, in contrast to Besley and Ghatak (2005) and Francois (2000, 2003 and 2004), our model predicts that for intermediate levels of output-motivation incentives are 'flat', despite the fact that the full-information outcome is not implementable. In general, in our model, high motivation makes it costly for the low-cost agent to over-report costs in order to produce less and thereby 
increase profits. Thus, intrinsic-motivation reduces the scope for external incentives.

The policy implications of these observations are clear. Namely, introducing high-powered incentives in the provision of public services and other collective goods, simply because such incentives seem to work well in the profit-maximising sector, may not be the best of practices. Another way to put this is to note that $\max _{\left\{q_{i} \geq 0\right\}_{i=1,2}}\left\{s\left[B\left(q_{1}\right)-\theta_{1} q_{1}-\pi\left(q_{1}, q_{2}, a, \Delta \theta\right)\right]+(1-\right.$ $s)\left[B\left(q_{2}\right)-\theta_{2} q_{2}\right]$ s.t. $\left.\pi\left(q_{1}, q_{2}, a, \Delta \theta\right) \geq 0\right\}$, that is, the expected net surplus (on the part of the principal) from the provision of public services is either negatively correlated or independent of the power of incentives for sufficiently low motivation (i.e. $a<a^{o}$ ). To see this note first that a straightforward application of the envelope theorem tells us that the expected net surplus is increasing if $a<a^{o}$. Second, recall from the above discussion that the power of incentives is decreasing with output-motivation if $a \in\left(0, \frac{\Delta \theta \hat{q}_{2}(a)}{B\left(\hat{q}_{1}(a)\right)-B\left(\hat{q}_{2}(a)\right)}\right)$, while incentives are flat if $a \in\left[\frac{\Delta \theta \hat{q}_{2}(a)}{B\left(\hat{q}_{1}(a)\right)-B\left(\hat{q}_{2}(a)\right)}, a^{o}\right)$. This result is similar to the relationship between incentives and the agent's expected productivity emphasised in Besley and Ghatak (2005).

We leave this Section by commenting upon the choice of missions in the provision of collective goods. Recall that the principal's net surplus depends on the agent's motivation, as the latter reduces the information rents on the part of the agent that are necessary for the agent to perform well (i.e. $P^{\prime}(a) \leq 0$ ). This implies that the choice, for instance, of a school's curriculum will affect the net expected returns from education. In fact, in terms of our model, the net surplus is increasing in the agent's output-motivation if $a<a^{o}$. This implies that, during a reform in the provision of collective goods, care must be taken so that agents do not become demotivated in the event of a change in the organisation's mission; that is, so that, in terms of our model, $a$ does not decrease. This is particularly important for nonprofit organisations that often accept donations which are conditional on the organisation's mission. It is also relevant for government-funded organisations, as, in this case, the government may attempt to influence the organisation's mission to bring it closer to the preferences of the electorate. These observations echo similar observations vis-a-vis an agency's expected productivity in Besley and Ghatak (2005). ${ }^{43}$

\footnotetext{
${ }^{43}$ In a related discussion, Prendercast (2007) discusses the problem of a principal who must hire and then incentivise, by means of imperfect monitoring, a bureaucrat who is responsible for recommending an allocation to a client. The recommendation is of better quality the more effort the bureaucrat exerts in collecting the necessary information. The client can instigate an investigation by complaining about the recommendation. The bureaucrat also is an altruist: he cares for the client's valuation of the allocation. The main result, then,
} 
Note now that an agent's net surplus from the provision of collective goods will also depend on the organisation's mission. In terms of our model, if $a<a^{o}$, then, at optimum, the high-productivity agent's net surplus is $a B\left(q_{1}^{*}(a)\right)+P(a)$, while the low-productivity agent's net surplus is $a B\left(q_{2}^{*}(a)\right)$. Thus an agent's surplus depends on her not-for-profit motive both directly and indirectly, through production and information rents. Recall from our discussion above that if $a \in\left(0, \frac{\Delta \theta \hat{q}_{2}(a)}{B\left(\hat{q}_{1}(a)\right)-B\left(\hat{q}_{2}(a)\right)}\right)$, then $P(a)>0$ with $P^{\prime}(a)<0$ and $q_{2}^{* \prime}(a)<0$. Also, if $a$ $\in\left[\frac{\Delta \theta \hat{q}_{2}(a)}{B\left(\hat{q}_{1}(a)\right)-B\left(\hat{q}_{2}(a)\right)}, a^{o}\right)$ then $P(a)=0$ and $q_{1}^{* \prime}(a)$ is ambiguous. Thus, the agent's net surplus can be decreasing with output-motivation, regardless of her productivity. In fact, this will be the case if (a) output is decreasing with intrinsic motivation and/or incentives are not flat, and (b) the corresponding negative welfare effects dominate the direct positive welfare effect of mission-motivation. ${ }^{44}$ This potential conflict of interest over the organisation's mission (i.e. a school's curriculum) between the principal (a school's board of governors) and the agent (a school's teachers) raises additional problems in the choice of the mission. Namely, changing the agency's goal may demotivate the agent (i.e. a may drop in terms of our model), and thereby raise the importance of monetary incentives. In addition, changing an organisation's mission may meet the opposition of the agency; that is, output-motivation on the part of agents may lead to conservatism. This is of particular importance for public bureaucracies, where the political principal, who may have her/his own views about the agency's goal or mission, is chosen by an electoral process. It may also explain why public bureaucracies are often accused of resisting innovation. Finally, this potential conflict of interest implies that empowering parents to intervene in schools' teaching methods and curriculums and enabling patients to intervene in the provision of health services may meet the opposition of education and health providers. ${ }^{45}$

is that in order to induce high effort the hired bureaucrat should in many cases be biased either against or in favour of the client, depending on the alignment between the preferences of the principal and the client.

${ }^{44}$ Note that if $a \geq a^{o}$ then the principal's surplus is independent of $a$, while the agent's welfare $a B\left(q^{o}\right)$ is increasing with her intrinsic motivation. Thus, in this range, increasing intrinsic motivation does not create a conflict of interest.

${ }^{45}$ See Besley and Ghatak (2005) for a related discussion. 


\section{Conclusions}

We have investigated a non-standard principal-agent model which we believe can be used to study government and other mission-orientated organisations. We have postulated that the relationship is hindered by an administrative constraint which requires budget appropriations to cover monetary production costs and that the agent is intrinsically motivated in that the agent values balanced-budget increases in output. The agency under investigation is thought of as the side with the monopoly of information about aspects of production.

In this paper we have assumed that the agent does not have an outside option. Nevertheless, our results are valid if the derived utility from this option is not too high. An interesting exercise would be to investigate the robustness of our results to the introduction of a highly valuable outside option for the agency.

Moreover, we have assumed that the only source of asymmetric information is the agent's productivity. In reality, however, the fixed cost could also be the private information of the bureau. In such an environment the principal will be faced with bidimensional asymmetric information. This would also be the case if the extent of the non-profit motivation was as well private knowledge of the agency. The investigation of the optimal design of the agency in the presence of multidimensional asymmetric information is a very interesting and challenging topic and is left for future research. ${ }^{46}$

In our model, the administrative constraint is present, and the agent values output over and above any monetary income she receives in the process. As we have seen the results differ significantly from those for the agent who is either intrinsically-motivated or wealth-constrained but not both. This leads us to conjecture that investigating further the case where the agent is both wealth-constrained and mission-motivated is worthwhile both from a theoretical point of view and for the deeper understanding of the operation of government and other nonprofit organisations.

For instance, one could investigate the case of many types. Many of the insights of our two type model, though not all, extend to the many-type case. In particular, subject to a regularity condition, which is similar though not the same as the one deployed in the standard model to ensure that there is no bunching of types, only the local upward incentive-compatibility

\footnotetext{
${ }^{46}$ For some related issues involved in multidimensional mechanism design see, for instance, Armstrong (1996) and Rochet and Chone (1998).
} 
constraints (that ensure that the $\theta_{i}$ - type does not mimic the $\theta_{i+1}-$ type with $\theta_{i+1}>\theta_{i}$ ) and the administrative constraints are relevant for the design of incentives. With no bunching, then, it is still optimal to give zero rents to the least productive type. It is also still true that the information rents of some types, which are necessary to prevent them from over-reporting costs, are decreasing with his intrinsic motivation and production, while they are increasing with the production of the immediately less productive type. Thus, external and internal incentives are still substitutes. Moreover, the least productive type under-produces, while the most productive type overproduces. Furthermore, for reasons similar to the ones in the twotype model, the rents given to more productive types may be zero. However, intermediate types may over- or under- produce. The reason is simple. To reduce the rents surrendered to more productive types, their production should be distorted downwards, as usual. To reduce their rents, on the other hand, their production should be distorted upwards, so the net effect is ambiguous.

One could also investigate the case of an informed principal, the case of repeated interactions, the presence of career concerns, the case of team-production, the cases of common agency and multi-tasking and the case of moral hazard for given productivity. These tasks are left for future research.

\section{Appendices}

\subsection{Appendix A}

Ignoring $q_{1} \geq 0,(7)$ the first order conditions (for the derivation of the optimal revelation mechanism) with respect to $\pi_{2}, \pi_{1}, q_{1}$ and $q_{2}$ are, respectively,

$$
\begin{aligned}
\mu_{2} & =\lambda_{1}+1-s \\
\lambda_{1} & =s-\mu_{1} \\
s\left[B^{\prime}\left(q_{1}\right)-\theta_{1}\right] & =-\lambda_{1} a B^{\prime}\left(q_{1}\right) \\
(1-s)\left[B^{\prime}\left(q_{2}\right)-\theta_{2}\right]+v & =\lambda_{1}\left[\Delta \theta+a B^{\prime}\left(q_{2}\right)\right],
\end{aligned}
$$

where $\mu_{1}$ is the Kuhn-Tucker multiplier of the low-cost agency's limited-liability constraint, $\mu_{2}$ is the Kuhn-Tucker multiplier of the high-cost agency's limited-liability constraint, $\lambda_{1}$ is the the Kuhn-Tucker multiplier of the low-cost agency's incentive-compatibility constraint, and $v$ is the 
Kuhn-Tucker multiplier of the high-cost agency's output non-negativity constraint. Moreover, we have the following complementary-slackness conditions:

$$
\begin{gathered}
\mu_{1} \geq 0, \pi_{1} \geq 0, \mu_{1} \pi_{1}=0, \\
\mu_{2} \geq 0, \pi_{2} \geq 0, \mu_{2} \pi_{2}=0, \\
\lambda_{1} \geq 0, \pi_{1}-\pi_{2}+a\left[B\left(q_{1}\right)-B\left(q_{2}\right)\right]-\Delta \theta q_{2} \geq 0, \\
\lambda_{1}\left[\pi_{1}-\pi_{2}+a\left[B\left(q_{1}\right)-B\left(q_{2}\right)\right]-\Delta \theta q_{2}\right]=0, \\
v \geq 0, q_{2} \geq 0, v q_{2}=0 .
\end{gathered}
$$

First, note that $\mu_{2}>0$ and thus $\pi_{2}=0$. Second note that if $\lambda_{1}=0$ then the above conditions imply that $\mu_{1}=s>0, \pi_{1}=0$ and $q_{i}=q_{i}^{o}$ for any $i=1,2$, which violate $\pi_{1}-\pi_{2}+a\left[B\left(q_{1}\right)-B\left(q_{2}\right)\right]-\Delta \theta q_{2} \geq 0$ given that $a<a^{o}$.

Therefore, $\lambda_{1}>0$ and $\pi_{1}-\pi_{2}+a\left[B\left(q_{1}\right)-B\left(q_{2}\right)\right]=\Delta \theta q_{2}$. This condition and $\pi_{2}=0$ imply that $\pi_{1} \geq 0$ can be re-written as $a B\left(q_{2}\right)+\Delta \theta q_{2} \geq a B\left(q_{1}\right)$. Note also that after eliminating $\mu_{2}$ and $\lambda_{1}$ from the first order conditions with respect to $q_{1}$ and $q_{2}$, we have that the latter become, respectively,

$$
\begin{aligned}
s\left[(1+a) B^{\prime}\left(q_{1}\right)-\theta_{1}\right] & =\mu_{1} a B^{\prime}\left(q_{1}\right) \\
(1-s)\left[B^{\prime}\left(q_{2}\right)-\theta_{2}\right]+v & =\left[s-\mu_{1}\right]\left[\Delta \theta+a B^{\prime}\left(q_{2}\right)\right],
\end{aligned}
$$

Clearly, these are the necessary conditions of problem (14) in the main text.

\subsection{Appendix B}

Consider the problem (14) in the main text:

$$
\max _{q_{1}, q_{2}} s\left[(1+a) B\left(q_{1}\right)-\left(a B\left(q_{2}\right)+\Delta \theta q_{2}+\theta_{1} q_{1}\right)\right]+(1-s)\left[B\left(q_{2}\right)-\theta_{2} q_{2}\right]
$$

subject to

$$
\begin{aligned}
q_{2} & \geq 0 \text { and } \\
a B\left(q_{2}\right)+\Delta \theta q_{2} & \geq a B\left(q_{1}\right) .
\end{aligned}
$$

Denote the solution with $q_{i}^{N}(a), i=1,2$. If $a B\left(\hat{q}_{2}(a)\right)+\Delta \theta \hat{q}_{2}(a) \geq a B\left(\hat{q}_{1}(a)\right)$ then the unconstrained solution $\hat{q}_{i}(a), i=1,2$, satisfies all the constraints, that can therefore be ignored. The unconstrained maximum has strictly positive output levels. That is, $q_{i}^{N}(a)=\hat{q}_{i}(a)>0$, 
with the inequality following from $\hat{q}_{1}(a)>q_{1}^{o}(a)>0$ and $a B\left(\hat{q}_{2}(a)\right)+\Delta \theta \hat{q}_{2}(a) \geq a B\left(\hat{q}_{1}(a)\right)>$ 0 . Note also that $\hat{q}_{1}(a)>q_{1}^{o}(a)>q_{2}^{o}(a)>\hat{q}_{2}(a)$. The latter follows from $1-s+s \frac{\Delta \theta}{\theta_{2}}>1-s-s a$.

Suppose now that the unconstrained maximum is not feasible. It follows then that the second constraint is binding. To see this note first that the first order conditions with respect to $q_{1}$ and $q_{2}$ are

$$
\begin{aligned}
s\left[(1+a) B^{\prime}\left(q_{1}\right)-\theta_{1}\right] & =\mu_{1} a B^{\prime}\left(q_{1}\right) \\
(1-s)\left[B^{\prime}\left(q_{2}\right)-\theta_{2}-\frac{s\left[a B^{\prime}\left(q_{2}\right)+\Delta \theta\right]}{1-s}\right]+\mu_{1}\left[a B^{\prime}\left(q_{2}\right)+\Delta \theta\right]+v & =0
\end{aligned}
$$

where $v$ and $\mu_{1}$ are the Kuhn-Tucker multipliers of the above constraints, respectively. If $\mu_{1}=0$ the above conditions imply that $q_{i}=\hat{q}_{i}(a)$ for any $i=1,2$. Given $a B\left(\hat{q}_{2}(a)\right)+$ $\Delta \theta \hat{q}_{2}(a)<a B\left(\hat{q}_{1}(a)\right)$ the second constraint is violated. Hence, $\mu_{1}>0$. Eliminating $\mu_{1}$ from the above conditions, we then have after some trivial re-arrangement of terms that $\frac{a B^{\prime}\left(q_{1}\right)}{a B^{\prime}\left(q_{2}\right)+\Delta \theta}=$ $-\frac{s\left[B^{\prime}\left(q_{1}\right)-\theta_{1}\right]}{(1-s)\left[B^{\prime}\left(q_{2}\right)-\theta_{2}\right]+v}$ and $\mu_{1}=\frac{s\left[(1+a) B^{\prime}\left(q_{1}\right)-\theta_{1}\right]}{a B^{\prime}\left(q_{1}\right)}>0$. The latter implies that $q_{1}^{N}(a)<\hat{q}_{1}(a)$. Moreover, the former condition implies, in conjuction with $B^{\prime}(0)>\theta_{2}$, that if $q_{2}=0$, then $q_{1}>q_{1}^{o}$. But $0<a B\left(q_{1}^{o}\right)$, so the condition $a B\left(q_{2}\right)+\Delta \theta q_{2} \geq a B\left(q_{1}\right)$ is violated when $q_{2}=0$. Thus $q_{2}>0$ and $v=0$. The fact that $\mu_{1}>0$, and hence $a B\left(q_{2}\right)+\Delta \theta q_{2}=a B\left(q_{1}\right)$, in conjuction with $q_{2}>0$, implies that $q_{1}>0$. Thus, $q_{i}^{N}(a)=\bar{q}_{i}(a)$. Notice now that due to $a<a^{o}, q_{1}^{o}>q_{2}^{o}>0$ and the properties of $B$, we have that $\bar{q}_{1}(a)>q_{1}^{o}(a)>q_{2}^{o}(a)>\bar{q}_{2}(a)>0$.

\subsection{Appendix C}

\section{This appendix is available upon request.}




\section{References}

Andreoni, J., 1988. Privately provided public goods in a large economy: the limits of altruism. Journal of Public Economics 35, 57-73.

Armstrong, M., 1996. Multiproduct nonlinear pricing. Econometrica 64, 51-75.

Baker, G., 1992. Incentive contracts and performance measurement. Journal of Political Economy 100, 598-614.

Banks, J.S., Weingast, B.R., 1992. The political control of bureaus under asymmetric information. American Journal of Political Science 36, 509-524.

Baron, D., Myerson, R., 1982. Regulating a monopolist with unknown costs. Econometrica 50, 911-930.

Barzelay, M., 2001. The New Public Management-improving Research and Policy Dialogue. Berkeley: University of California Press.

Benabou, R., Tirole, J., 2003. Intrinsic and extrinsic motivation. Review of Economic Studies $70,489-520$.

Bendor, J., Taylor, S., van Gaalen, R., 1985. Bureaucratic expertise vs. legislative authority: a model of deception and monitoring in budgeting. American Political Science Review 79, 1041-1060.

Bennett, J., Iossa, E., 2005. Contracting out public service provision to non-for-profit firms. 05-14 Public Policy Discussion Paper, Economics and Finance Section, School of Social Sciences, Brunel University.

Besley, T., Ghatak, M., 2005. Competition and incentives with motivated Agents. American Economic Review 95, 3, 616-636.

Burgess, S., Metcalfe, P., 1999. Incentives in organisations: a selective overview of the literature with application to the public sector. CMPO Working Paper No 99/016.

Burgess, S., Ratto, M., 2003. The role of incentives in the public sector: issues and evidence. CMPO Working Paper No 03/071. 
Calvert, R., McCubbins, M.D., Weingast, B.R., 1989. A theory of political control and agency discretion. American Journal of Political Science 33, 588-611.

Che, Y., Gale, I., 2000. The Optimal mechanism for selling to a budget-constrained buyer. Journal of Economic Theory 92, 198-233.

Delfgaauw, J., Dur, R., 2007. Signaling and screening of workers' motivation. Journal of Economic Behavior and Organization 62, 605-24.

Delfgaauw, J., Dur, R., 2008. Incentives and workers' motivation in the public sector. Economic Journal 118, 171-191.

Dewatripont, M., Jewitt, I., Tirole, J., 1999. The economics of career concerns. part II: application to missions and accountability of government agencies. Review of Economic Studies 66, 199-217.

Dixit, A.K., 1997. Power of incentives in private versus public organizations. American Economic Review, Papers and Proceedings 87, 378-82.

Dixit, A.K., 2002a. Incentives and organizations in the public sector: an interpretative review. Journal of Human Resources 37, 696-727.

Dixit, A.K., 2002b. Incentive contracts for faith-based organizations to deliver social services. mimeo.

Francois, P., 2000. Public service motivation as an argument for government provision. Journal of Public Economics 78, 777-95.

Francois, P., 2003. Not-for-profit provision of public services. Economic Journal 113, C53-61.

Francois, P., 2004. 'Making a difference': Labour donations in the production of public goods. CMPO W/P 04/093.

Glazer, A., 2004. Motivating devoted workers. International Journal of Industrial Organisation $22,427-440$.

Grout, P.A. Stevens, M., 2003. Financing and managing public services: an assessment. CMPO Working Paper No 03/071. 
Grout, P.A., Young, M.J., 2003. The role of donated labour and not for profit at the public/private interface. CMPO Working Paper No 03/074.

Heckman, J., Heinrich, C., and Smith, J., 1997. Assessing the performance standards in public bureaucracies. American Economic Review, Papers and Proceedings 87, 389-95.

HM Treasury, 2000. Public Services: Meeting the Productivity Challenge. UK: Public Service Productivity Panel. Available at http://archive.treasury.gov.uk/pdf/2000/psppjoint0108.pdf.

Horn, M.J., 1995. The Political Economy of Public Administration. Cambridge: Cambridge University Press.

Hoxby, C.M., 1999. The productivity of schools and other local public goods producers. Journal of Public Economics 74, 1-30.

Kreps, D.M., 1997. Intrinsic motivation and extrinsic incentives. American Economic Review, Papers and Proceedings 87, 359-64.

Laffont, J.J., Martimort, D., 2002. The Theory of Incentives: The Principal-Agent Model. Princeton: Princeton University Press.

Laffont, J.J., Tirole, J., 1993. A Theory of Incentives in Procurement and Regulation. Cambridge, Massachusetts: MIT Press.

Mas-Colell, A., Whinston, M.D., Green, J.R., 1995. Microeconomic Theory. New York: Oxford University Press.

McCubbins, M.D., 1985. The Legislative design of regulatory structure. American Journal of Political Science 29, 721-748.

Murdock, K., 2002. Intrinsic motivation and optimal incentive contract. RAND Journal of Economics 33, 650-71.

Niskanen, W.A., 1971. Bureaucracy and Representative Government. New York: AldineAtherton.

Novaes, W., Zingales, L., 2003. Bureaucracy as a mechanism to generate information. CEPR $\mathrm{D} / \mathrm{P} 3945$. 
Osborne, D. Gaebler, T., 1993. Reinventing Government: How the Entrepreneurial Spirit is Transforming the Public Sector. New York: Plume Books.

Prendergast, C., 2003. The limits of bureaucratic efficiency. Journal of Political Economy $111,929-58$.

Prendergast, C., 2007. The motivation and bias of bureaucrats. The American Economic Review 97, 1, 180-196.

Propper, C. Wilson, D., 2003. The use and usefulness of performance measures in the public sector. CMPO W/P No 03/073.

Rochet, J.C., Chone, P., 1998. Ironing, sweeping and multidimensional screening. Econometrica $66,783-826$.

Rose-Ackerman, S., 1986. Reforming public bureaucracy through economic incentives? Journal of Law, Economics, and Organization 2, 131-61.

Sappington, D., 1983. Limited liability contracts between principal and agent. Journal of Economic Theory 29, 1-21.

Tirole, J., 1994. The internal organisation of government. Oxford Economic Papers 46, 1-29.

Wilson, J.Q., 1989. Bureaucracy: What Government Agencies Do and Why They Do It. New York: Basic Books. 